\title{
Commentary: Systemic, Local, and Imaging Biomarkers of Brain Injury: More Needed, and Better Use of Those Already Established?
}

\author{
Marcelo de Lima Oliveira ${ }^{1 *}$, Edson Bor-Seng-Shu ${ }^{1}$, Renata Faria Simm ${ }^{1}$, \\ Tatiana Vilas Boas ${ }^{1}$ and Paulo Henrique Pires Aguiar ${ }^{2}$ \\ ${ }^{1}$ Neurology Department, Hospital Santa Paula, São Paulo, Brazil, ${ }^{2}$ Surgical Department, Universidade Federal do Rio \\ Grande do Sul, São Paulo, Brazil
}

Keywords: cerebral metabolic crises, traumatic brain injury, mitochondrial dysfunction, glucose metabolism, subarachnoid hemorrhage

\section{OPEN ACCESS}

Edited by:

George E. Barreto,

Pontificia Universidad Javeriana,

Colombia

Reviewed by:

Marco G. Alves,

Health Sciences Research Center,

Portugal

Thad A. Rosenberger, University of North Dakota School of Medicine and Health Sciences, USA

${ }^{*}$ Correspondence: Marcelo de Lima Oliveira marcelodtc@gmail.com

Specialty section:

This article was submitted to Neurotrauma

a section of the journal

Frontiers in Neurology

Received: 18 January 2016

Accepted: 29 February 2016

Published: 21 March 2016

Citation:

de Lima Oliveira M, Bor-Seng-Shu E,

Simm RF, Vilas Boas T and Pires Aguiar PH (2016) Commentary:

Systemic, Local, and Imaging

Biomarkers of Brain Injury: More Needed, and Better Use of Those

Already Established?

Front. Neurol. 7:34.

doi: 10.3389/fneur.2016.00034

\section{A commentary on}

Systemic, Local, and Imaging Biomarkers of Brain Injury: More Needed, and Better Use of Those Already Established?

by Carpenter KLH, Czosnyka M, Jalloh I, Newcombe VFJ, Helmy A, Shannon RJ, et al. Front Neurol (2015) 6: 26. doi: 10.3389/fneur.2015.00026

Cerebral metabolism plays an important role in maintaining cell functions. The brain requires glucose as the main substrate for aerobic glycolysis to sustain the high cerebral metabolic demands. Glucose transport through the blood-brain barrier is mediated by GLUT1 glucose transporter protein. Higher cerebral metabolic needs may increase GLUT1 expression on microvessels, thus enhancing glucose uptake (1). Therefore, glucose is the only substrate that is transported across the $\mathrm{BBB}$ at a sufficient rate. Cerebral ischemia is classically defined as a cellular condition in which there is insufficient glucose and oxygen for energy production $(2,3)$.

Some authors have described cerebral metabolic crisis (MC) that is related to alterations in the use of glucose for energy synthesis, traumatic brain injury (TBI), and subarachnoid hemorrhage (SAH) (4-7). What process does the term "cerebral MC" actually describe? To understand this issue, it is important to identify the two major pathways that produce neuronal energy: (1) an aerobic path in which 1 glucose molecule results in 38 ATP molecules and $\mathrm{H}_{2} \mathrm{O}$ and (2) an anaerobic path in which 1 glucose molecule results in 2 ATP molecules and 2 molecules of lactate. Both of these pathways use glycolysis to convert glucose to pyruvate, which is the main substrate needed to provide energy (8). Thus, energy biomarkers, such as glucose, lactate, and pyruvate, provide relevant information describing cerebral metabolism. During cerebral tissue hypoxia, energy is mainly produced anaerobically. The restoration of cerebral blood flow and oxygenation within a proper time frame leads to the normalization of aerobic cell respiration if the mitochondrial function is still preserved. However, during mitochondrial dysfunction in which neuronal cells are unable to use the available tissue oxygen, the anaerobic (redox) pathway is also used; mitochondrial dysfunction can occur due to or during decreased blood flow and may also occur in the normal blood flow/hyperemia state $(2,6,9)$. Both ischemia and mitochondrial dysfunction states produce lactate with high pyruvate consumption, resulting in an increased lactate/pyruvate ratio (L/P) type 1 (10). However, cerebral $\mathrm{MC}$ can occur in the absence of high lactate levels and are classified as L/P type 2 characterized by decreased pyruvate synthesis. MCs can occur during a variety of pathological cellular states, such 
as TBI, SAH, stroke, and meningitis, and may be associated with high or normal levels of oxygen in the cerebral tissue.

Carpenter et al. (3) determined that an increased $\mathrm{L} / \mathrm{P}$ ratio is a consequence of the redox state. However, there are other cerebral MCs. It is important to reinforce the following concepts regarding MCs: (1) mitochondrial dysfunction is a MC associated with an increased L/P type 1 and redox state, (2) other MCs may be linked to a shift from glucose metabolism to other functions in neuronal cells and are associated with an increased L/P type 2, (3) glucose is not the only substrate used to produce energy in neuronal cells, and (4) different cerebral MCs may occur simultaneously.

Some cerebral MCs are characterized by decreased glucose metabolism. Thus, other substances may be used to produce cerebral cellular energy. Lactate can be oxidized in the brain and may be an energy source. Furthermore, peripheral lactate reaches the liver, where it stimulates glucose production via gluconeogenesis and provides glucose to the brain to restore glucose metabolism (11). Moreover, cerebral uptake of lactate increases during intense exercise without high levels of CSF lactate. Thus, lactate is oxidized to be used as fuel, sparing glucose, and is eliminated by the brain, similar to the liver (12). Additionally, in reversible ischemia, LPR normalizes within 60-90 min of CBF restoration; this finding reinforces that accumulated lactate can be aerobically used (8). Another study suggested that ketones are oxidizable substances that may be used as substrates to produce energy and can lead to improved energy status $(4,13,14)$. Furthermore, a ketogenic diet reduces the lactate levels and improves the ATP levels after TBI in juvenile rats (13). Therapy with branched chain amino acids after percussion TBI improved synapse efficiency and cognitive performance in adult mice possibly by normalizing brain levels of this amino acid, which has a role in glutamate metabolism (13). Conversely, glucose metabolism may increase during a TBI.

\section{REFERENCES}

1. Simpson IA, Appel NM, Hokari M, Oki J, Holman GD, Maher F, et al. Bloodbrainbarrierglucose transporter:effects of hypo-andhyperglycemiarevisited. J Neurochem (1999) 72(1):238-47. doi:10.1046/j.1471-4159.1999.0720238.x

2. De Lima Oliveira M, Kairalla AC, Fonoff ET, Martinez RC, Teixeira MJ, Bor-Seng-Shu E. Cerebral microdialysis in traumatic brain injury and subarachnoid hemorrhage: state of the art. Neurocrit Care (2014) 21:152-62. doi:10.1007/s12028-013-9884-4

3. Carpenter KL, Czosnyka M, Jalloh I, Newcombe VF, Helmy A, Shannon RJ, et al. Systemic, local, and imaging biomarkers of brain injury: more needed, and better use of those already established? Front Neurol (2015) 6:26. doi:10.3389/fneur.2015.00026

4. Vespa P, Bergsneider M, Hattori N, Wu HM, Huang SC, Martin NA, et al. Metabolic crisis without brain ischemia is common after traumatic brain injury: a combined microdialysis and positron emission tomography study. J Cereb Blood Flow Metab (2005) 25:763-74. doi:10.1038/ sj.jcbfm. 9600073

5. Ho CL, Wang CM, Lee KK, Ng I, Ang BT. Cerebral oxygenation, vascular reactivity, and neurochemistry following decompressive craniectomy for severe traumatic brain injury. J Neurosurg (2008) 108:943-9. doi:10.3171/ JNS/2008/108/5/0943
In the presence of oxidative stress, glucose metabolism is diverted to the pentose phosphate pathway (PPP). This pathway produces a reduction equivalent in the form of NADPH, which plays a cellular protective role by removing free radicals through its action over glutathione. Ketones may play the same PPP role of increasing antioxidants and scavenging free radicals, which mediate mitochondrial function (15). Glutathione peroxidase is a key antioxidant enzyme that is elevated at $3 \mathrm{~h}$ and peaks 7 days post-traumatic brain injury. The PPP also produces ribose, which is important for DNA repair and replication and for mRNA and protein synthesis. The PPP is responsible for approximately $2-5 \%$ of glucose utilization during normal metabolism but can reach levels exceeding $8-12 \%$ after TBI $(2,16)$.

During these cited conditions, pyruvate synthesis is reduced, and the L/P type 2 increases (10). These findings suggest that cerebral MCs are not restricted to the condition of high lactate synthesis that occurs during ischemia and mitochondrial dysfunction. Importantly, free radicals, which are associated with ischemia, can cause mitochondrial failure and consequently reduce oxidative metabolism; furthermore, glucose may be used to remove free radicals. Thus, mitochondrial dysfunction and other MCs may coexist.

We emphasize that MCs consist of a broad spectrum of glucose and other energy synthesis disturbances. The diagnoses of different MCs may increase treatment options for "cell symptoms" and could improve patient prognosis.

\section{AUTHOR CONTRIBUTIONS}

MLO: author and writer, EBSS: general article reviewer, RFS: drafting the work, TVB: reviewer about general metabolic crises treatment, and PHPA: final approval for article publication.

6. Bor-Seng-Shu E, de Lima Oliveira M, Teixeira MJ. Letter to the editor. Traumatic brain injury and metabolism. J Neurosurg (2010) 112:1351-3. doi:10.3171/2009.10.JNS091426

7. Bor-Seng-ShuE, FigueiredoEG, Amorim RL, Teixeira MJ, Valbuza JS, de Oliveira MM, et al. Decompressive craniectomy: a meta-analysis of influences on intracranial pressure and cerebral perfusion pressure in the treatment of traumatic brain injury. J Neurosurg (2012) 117:589-96. doi:10.3171/2012.6.JNS101400

8. De Lima Oliveira M, Paiva W, Teixeira MJ, Bor-Seng-Shu E. Brain metabolic crisis in traumatic brain injury: what does it mean? J Neurotrauma (2014) 31:1750-1. doi:10.1089/neu.2014.3386

9. De Lima Oliveira M, de Azevedo DS, de Azevedo MK, de Carvalho Nogueira R, Teixeira MJ, Bor-Seng-Shu E. Encephalic hemodynamic phases in subarachnoid hemorrhage: how to improve the protective effect in patient prognoses. Neural Regen Res (2015) 10:748-52. doi:10.4103/1673-5374.156969

10. Hillered L, Persson L, Nilsson P, Ronne-Engstrom E, Enblad P. Continuous monitoring of cerebral metabolism in traumatic brain injury: a focus on cerebral microdialysis. Curr Opin Crit Care (2006) 12:112-8. doi:10.1097/01. ccx.0000216576.11439.df

11. Glenn TC, Martin NA, Horning MA, McArthur DL, Hovda DA, Vespa P, et al. Lactate: brain fuel in human traumatic brain injury: a comparison with normal healthy control subjects. J Neurotrauma (2015) 32:820-32. doi:10.1089/ neu.2014.3483 
12. Quistorff B, Secher NH, Van Lieshout JJ. Lactate fuels the human brain during exercise. FASEB J (2008) 22:3443-9. doi:10.1096/fj.08-106104

13. McKenna MC, Scafidi S, Robertson CL. Metabolic alterations in developing brain after injury: knowns and unknowns. Neurochem Res (2015) 40(12):2527-43. doi:10.1007/s11064-015-1600-7

14. Valente-Silva P, Lemos C, Köfalvi A, Cunha RA, Jones JG. Ketone bodies effectively compete with glucose for neuronal acetyl-CoA generation in rat hippocampal slices. NMR Biomed (2015) 28:1111-6. doi:10.1002/ nbm. 3355

15. Greco T, Glenn TC, Hovda DA, Prins ML. Ketogenic diet decreases oxidative stress and improves mitochondrial respiratory complex activity. J Cereb Blood Flow Metab (2015). doi:10.1177/0271678X15610584

16. Bartnik BL, Sutton RL, Fukushima M, Harris NG, Hovda DA, Lee SM. Upregulation of pentose phosphate pathway and preservation of tricarboxylic acid cycle flux after experimental brain injury. J Neurotrauma (2005) 22:105265. doi:10.1089/neu.2005.22.1052

Conflict of Interest Statement: The authors declare that the research was conducted in the absence of any commercial or financial relationships that could be construed as a potential conflict of interest.

Copyright $\odot 2016$ de Lima Oliveira, Bor-Seng-Shu, Simm, Vilas Boas and Pires Aguiar. This is an open-access article distributed under the terms of the Creative Commons Attribution License (CC BY). The use, distribution or reproduction in other forums is permitted, provided the original author(s) or licensor are credited and that the original publication in this journal is cited, in accordance with accepted academic practice. No use, distribution or reproduction is permitted which does not comply with these terms. 